Research Journal of Pharmacology 5 (3): 27-30, 2011

ISSN: $1815-9362$

(C) Medwell Journals, 2011

\title{
Effect of Ceftriaxone on Isolated Gastrointestinal Muscles
}

\author{
M.G. Elsayed, A.A. Elkomy and M.H. Aboubakr \\ Department of Pharmacology, Faculty of Veterinary Medicine, \\ Benha University, 13736 Moshtohor, Toukh, Qalioubeya, Egypt
}

\begin{abstract}
The pharmacodynamic effect of ceftriaxone on smooth muscles was investigated in isolated organs. Maximum stimulation of isolated guinea pig's ileum and rabbit's duodenum and rat's fundic strip was achieved by addition of $1024 \mu \mathrm{g}$ of ceftriaxone $\mathrm{mL}^{-1}$ bath. While in isolated rat's colon, it was achieved by $512 \mu \mathrm{g}$ of ceftriaxone $\mathrm{mL}^{-1}$ bath. Trials were performed to locate the site of action of ceftriaxone on the guinea pig's ileum, rabbit's duodenum and rat's colon. After blocking the ganglia with large dose of nicotine and addition of atropine sulphate as muscarinic cholinergic receptor blocker, ceftriaxone was able to produce its stimulatory effect. Adrenaline was able to produce its inhibitory effect in presence of ceftriaxone. The above mentioned trials indicated that ceftriaxone might have a direct stimulatory effect on the ileal, duodenal and colon smooth muscles. Ceftriaxone in concentration of $1024 \mu \mathrm{g} \mathrm{mL}^{-1}$ bath has a serotonin like effect on rat's fundic strip.
\end{abstract}

Key words: Ceftriaxone, gastrointestinal, ileum, duodenum, colon, fundus

\section{INTRODUCTION}

Ceftriaxone is a broad spectrum cephalosporin resistant to various types of beta-lactamases with potent activity against gram-positive and gram-negative bacteria including Enterobacteriaceae, Haemophilus influenzae, Streptococcus pneumoniae and other nonenterococcal streptococci, Methicillin-resistant staphylococci, Enterococci, Pseudomonas aeruginosa and Bacteroides fragilis were typically resistant (Neu et al., 1981). The drug acts through inhibition of transpeptidase enzymes responsible for the final step in bacterial cell wall synthesis (Waxam and Strominger, 1982) and has broad stability against beta-hydrolysis ( $\mathrm{Neu}, 1985)$. In human medicine, ceftriaxone is widely used because of its prolonged terminal half-life (5.4-8.2 h) that allows its prescription on a single administration per day basis (Patel et al., 1982; Meyers et al., 1983; Ti et al., 1984; Zhou et al., 1985; Bourget et al., 1993). So, expanded informations concerning the pharmacodynamic effects of ceftriaxone will be of benefits to physicians and their patients. The present study was aimed to study pharmacodynamic aspects of ceftriaxone on isolated gastrointestinal smooth muscles.

\section{MATERIALS AND METHODS}

Drug: Ceftriaxone is a sterile, semisynthetic, broadspectrum 3rd generation cephalosporin antibiotic for intravenous or intramuscular administration. Ceftriaxone is a white to yellowish-orange crystalline powder which is readily soluble in water, sparingly soluble in methanol and very slightly soluble in ethanol. The $\mathrm{pH}$ of a $1 \%$ aqueous solution is approximately 6.7. It was produced by Smithkline Beecham for Novartis Pharma Company (Egypt) and has the commercial name Ceftriaxone ${ }^{\circledR}$.

Perfusion fluids for pharmacological experiments: The isolated guinea pig's ileum, rabbit's duodenum and rat's colon was suspended in the organ bath containing warm oxygenated tyrod's solution at $37^{\circ} \mathrm{C}$. While rat's fundic strip was suspended in the organ bath containing warm oxygenated Kreb's ringer solution at $37^{\circ} \mathrm{C}$. The above mentioned physiological salt solutions were prepared as indicated by staff members of the University of Edinburgh, Department of Pharmacology (1970).

\section{Chemicals}

- Nicotine sulphate (Hopkin and Williams Company, England)

- Atropine sulphate (Memphis Company, Cairo, Egypt)

- Adrenaline (Cid, Giza, Egypt)

Glass jar bath: A glass water bath of about $750 \mathrm{~mL}$ capacity fitted into a metal stand in which a movable electric heater was located to maintain the temperature as requied. An inner glass tube (organ bath) of $40 \mathrm{~mL}$ capacity passed through the bottom of the stand and was connected by a T-shaped glass tube.

Harvard universal oscillographe and transducers: Two channels curvilinear oscillograph (Harvard UK) with an isotonic transducer (Harvard App. Ltd.) which was employed for recording the effect of ceftriaxone on

Corresponding Author: M.H. Aboubakr, Department of Pharmacology, Faculty of Veterinary Medicine, Benha University, 13736 Moshtohor, Toukh, Qalioubeya, Egypt 
isolated tissues. The method explained by Valeri et al. (1990) was used for studying the effect of ceftriaxone on the isolated ileum of guinea pigs. The method described by the staff members of Pharmacology Department, University of Edinburg UK, 1968 was used for studying the effect of ceftriaxone on isolated rabbit's duodenum and rat's colon. The effect of ceftriaxone on isolated rat's fundic strip was investigated according to the method described by Milenov and Kalfin (1996).

\section{RESULTS AND DISCUSSION}

The effect of ceftriaxone on isolated guinea pig's ileum, rabbit's duodenum, rat's colon and rat's fundic strip were shown in Table 1. The maximum stimulant effect of ceftriaxone on isolated guinea pig's ileum, rabbit's duodenum, rat's colon and rat's fundic strip were shown in Fig. 1a-d. The site of action of ceftriaxone on isolated guinea pig's ileum, rabbit's duodenum, rat's colon and rat's fundic strip were shown in Fig. 2a-d. The stimulant effect of ceftriaxone on the isolated intestinal smooth muscle preparations might be attributed to its direct effect. Ceftriaxone in concentration of $1024 \mu \mathrm{g} \mathrm{mL} \mathrm{m}^{-1}$ bath has a serotonin like effect on rat's fundic strip.

The present investigation showed that ceftriaxone in vitro stimulated the contractility of guinea pig's ileum, rat's colon and rabbit's duodenum. The stimulatory effect of ceftriaxone was proportional to the graded tested concentrations. Presence of atropine sulphate as muscarinic cholinergic receptor blocker and large dose of nicotine sulphate as ganglionic (Nicotinic receptor) blocker did not inhibit the stimulatory effect of ceftriaxone. In addition, the adrenaline as adrenoceptor agonist produced its inhibitory effect in presence of ceftriaxone. These results proved that ceftriaxone might directly stimulates the intestinal smooth muscles of rabbit's duodenum, guinea pig's ileum and rat's colon. These obtained results were similar to those obtained by Takai et al. (1980) who found that cefeperazone in vivo enhanced the ileal motility in guinea pigs at 62.5 and $125 \mathrm{mg} \mathrm{kg}^{-1}$, respectively and in vitro enhanced slightly the motility of isolated rabbit's gastrointestinal tract at $0.001 \mathrm{~g} \mathrm{~mL}^{-1}$. Also, these results were similar with those obtained by Yamaki et al. (1984) who stated that the spontaneous motility of smooth muscle was temporarily increased with $800 \mathrm{mg} \mathrm{kg}^{-1}$ cefminox when administered intravenously and in upper doses. In contrast, Hasegawa et al. (1979) stated that cefadroxil had no effects on the isolated smooth muscle organs in mice. In addition, Honda et al. (1980) stated that ceftizoxime sodium neither affected the spontaneous motility of isolated rabbits's and guinea pig's ileum at concentration equal to $10^{-2} \mathrm{~g} \mathrm{~mL}^{-1}$ nor interacted with acetylcholine or histamine on the isolated guinea-pig's preparation. Takai et al. (1982) found that the spontaneous movement
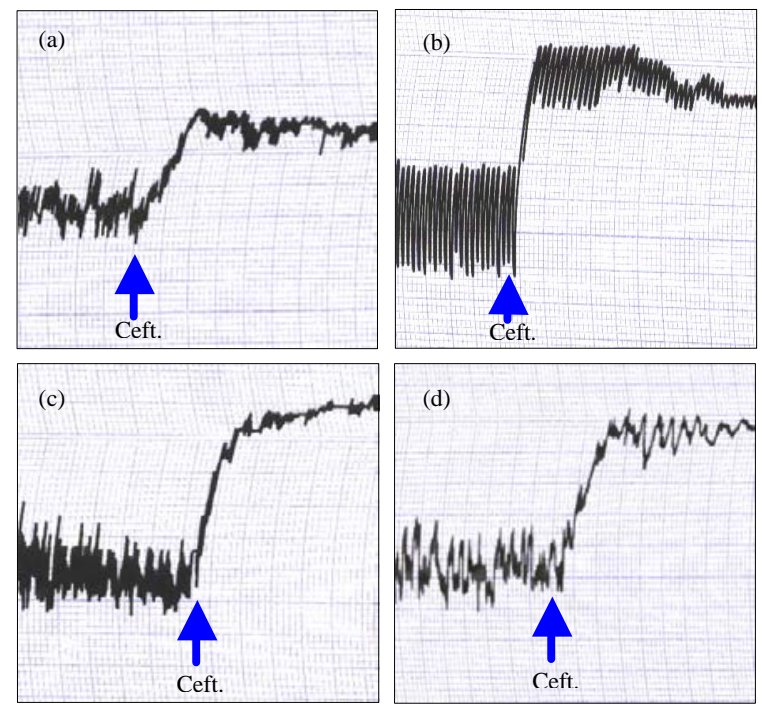

Fig. 1: Effect of Ceftriaxone (Ceft.) on isolated gastrointestinal muscles: a) $1024 \mu \mathrm{g} \mathrm{mL} \mathrm{m}^{-1}$ bath Ceftriaxone (Ceft.) on isolated guinea pig's ileum; b) $1024 \mu \mathrm{g} \mathrm{mL} \mathrm{m}^{-1}$ bath Ceftriaxone (Ceft.) on isolated rabbit's duodenum; c) $512 \mu \mathrm{g} \mathrm{mL} \mathrm{m}^{-1}$ bath Ceftriaxone (Ceft.) on isolated rat's colon and d) $1024 \mu \mathrm{g} \mathrm{mL}{ }^{-1}$ bath Ceftriaxone (Ceft.) on isolated rat's fundic strip

Table 1: The effect of ceftriaxone on isolated guinea pig's ileum, rabbit's duodenum, rat's colon and rat's fundic strip Responses of

\begin{tabular}{|c|c|c|c|c|}
\hline \multirow{2}{*}{$\begin{array}{l}\text { Concentrations } \\
\text { ( } \mu \mathrm{g} \mathrm{mL}^{-1} \text { bath) }\end{array}$} & \multicolumn{4}{|l|}{ nises or } \\
\hline & Guinea pig's ileum & Rabbit's duodenum & Rat's colon & Rat's fundic strip \\
\hline 8 & No effect & No effect & No effect & No effect \\
\hline 16 & No effect & Slight stimulation in the force & Slight stimulation in the force & No effect \\
\hline 32 & Slight stimulation in the force & Slight stimulation in the force & Slight stimulation in the force & No effect \\
\hline 64 & Slight stimulation in the force & Slight stimulation in the force & Slight stimulation in the force & Slight stimulation in the force \\
\hline 128 & Slight stimulation in the force & Slight stimulation in the force & $\begin{array}{l}\text { Marked inhibition in the force and } \\
\text { rate of contraction }\end{array}$ & Slight stimulation in the force \\
\hline 256 & $\begin{array}{l}\text { Marked inhibition in } \\
\text { the force and rate of contraction }\end{array}$ & $\begin{array}{l}\text { Marked inhibition in the } \\
\text { force and rate of contraction }\end{array}$ & $\begin{array}{l}\text { Marked inhibition in the force } \\
\text { and rate of contraction contraction }\end{array}$ & $\begin{array}{l}\text { Marked inhibition in } \\
\text { the force and rate of }\end{array}$ \\
\hline 512 & $\begin{array}{l}\text { Marked inhibition in the force } \\
\text { and rate of contraction }\end{array}$ & $\begin{array}{l}\text { Marked inhibition in the force } \\
\text { and rate of contraction }\end{array}$ & Maximum stimulation & $\begin{array}{l}\text { Marked inhibition in the force } \\
\text { and rate of contraction }\end{array}$ \\
\hline 1024 & Maximum stimulation & Maximum stimulation & - & Maximum stimulation \\
\hline
\end{tabular}


Res. J. Pharmacol., 5(3): 27-30, 2011
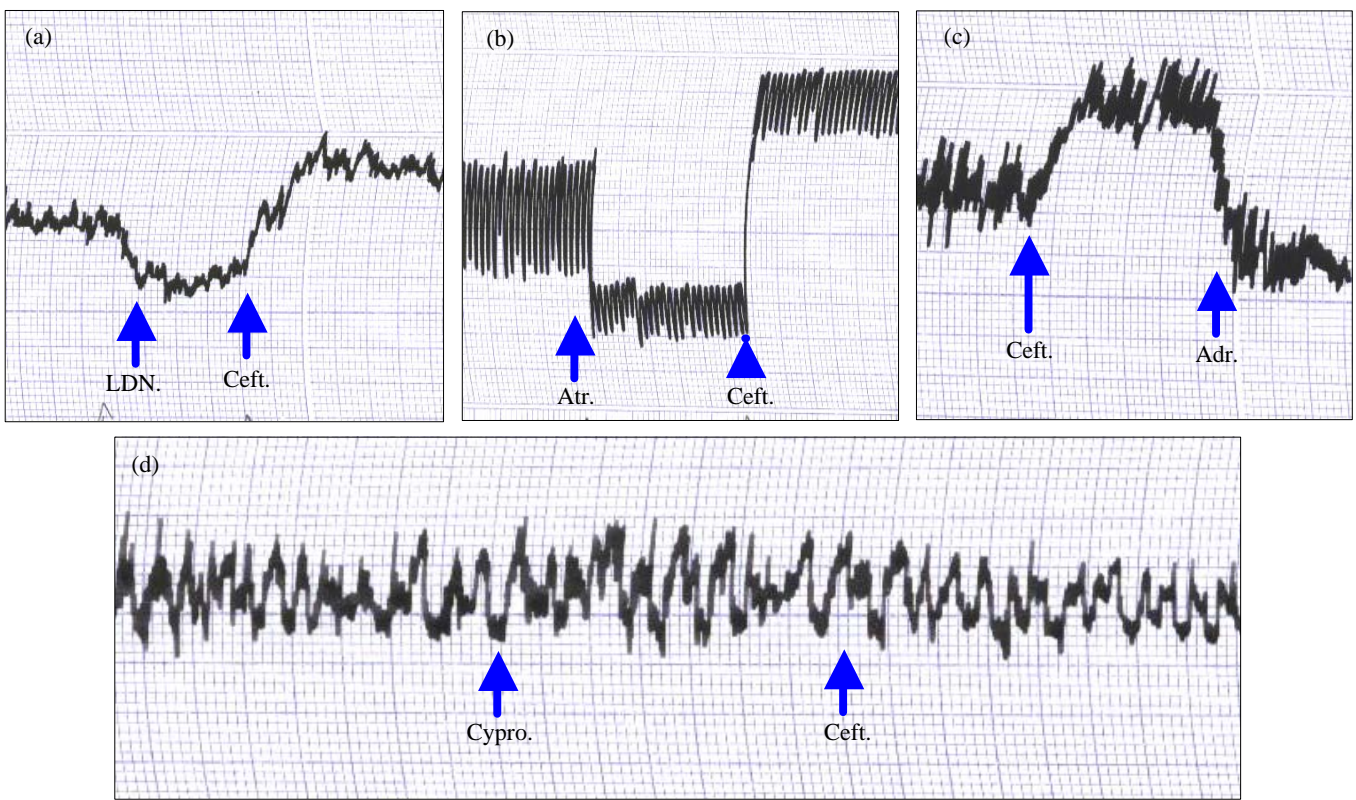

Fig. 2: Site of action of Ceftriaxone (Ceft.) on isolated gastrointestinal muscles: a) $5 \mu \mathrm{g} \mathrm{mL} \mathrm{L}^{-1}$ bath nicotine sulphate (LDN.) followed by $256 \mu \mathrm{g} \mathrm{mL}{ }^{-1}$ bath Ceftriaxone (Ceft.) on isolated guinea pig's ileum; b) $1 \mu \mathrm{g} \mathrm{mL}{ }^{-1}$ bath atropine sulphate (Atr.) followed by $256 \mu \mathrm{g} \mathrm{mL}{ }^{-1}$ bath Ceftriaxone (Ceft.) on isolated rabbit's duodenum; c) 256 $\mu \mathrm{g} \mathrm{mL}{ }^{-1}$ bath Ceftriaxone (Ceft.) followed by $0.5 \mu \mathrm{g} \mathrm{mL}^{-1}$ bath Adrenaline (Adr.) on isolated rat's colon and d) Cyproheptadine $5 \times 10^{-6} \mathrm{mmol}$ (Cypro.) followed by $1024 \mu \mathrm{g} \mathrm{mL}{ }^{-1}$ bath Ceftriaxone (Ceft.) on isolated rat's fundic strip

and tone of isolated ileum, colon and acetylcholine-, histamin-, nicotine- or barium chloride-induced contraction of ileum were not affected following cefbuperazone application. Further more, Goto et al. (1990) recorded that cefprozil did not affect the isolated smooth muscles of rat's uterus, guinea pig's ileum or rabbit's duodenum and did not influence ganglionic transmission in cats. Goto et al. (1992) stated also that cefetriaxone had no effect on the intestinal smooth muscle and did not show any antagonism against some smooth muscle contracting drugs. El-Sayed et al. (1997) proved that cefamandole at concentrations of 512 and 1024 micrograms $\mathrm{mL}^{-1}$ bath caused complete relaxation in isolated guinea pig's ileum and rabbit's duodenum, respectively. Ceran et al. (2006) found that maximum contractile responses to carbachol and histamine were significantly reduced in response to the ceftriaxone sodium. Ceftriaxone stimulated contractility of the rat's fudnic strip. This stimulatory effect was dose dependant. Ceftriaxone in a high concentration produce a serotonin like effect on rat's fundic strip (a sensetive preparation for detection of serotonin). These results might be attributed to the ability of ceftriaxone to release serotonin from its stores. The seotonin stimulating effect of ceftriaxone overcomed its direct effect on the smooth muscle of rat's fudnic strip. The obtained results came in harmony with those obtained by Jankovic et al. (1996) recorded that cefotaxime, ceftriaxone and ceftazidime cefamandole had stimulatory effect on the rat's fundic strips. On the other hand, Honda et al. (1980) who stated that ceftizoxime sodium after intravenous dose of $320-1000 \mathrm{mg} \mathrm{kg}^{-1}$ dose-dependently suppressed spontaneous contraction of the pyloric part in morphine-urethane-anesthetized dogs. Hasegawa et al. (1979) recorded that cefadroxil had no effects on the motility of the stomach in rabbits.

\section{CONCLUSION}

These findings indicated that ceftriaxone had stimulatory effect on isolated gastrointestinal smooth muscles.

\section{REFERENCES}

Bourget, P., H. Fernandez, V. Quinquis and C. Delouis, 1993. Pharmacokinetics and protein binding of ceftriaxone during pregnancy. Antibiotic Agents Chemother., 37: 54-59.

Ceran, C., B. Karadas, T. Kaya, M. Arpacik, I. Bagcivan and B. Sarac, 2006. Do antibiotics contribute to postoperative ileus: Contractile responses of ileum smooth muscle in Guinea pigs to long-term parenteral ceftriaxone and ampicillin. ANZ. J. Surg., 76: 1023-1026. 
El-Sayed, M.G., M.R. Hassanin, M.H. Hafez, A.A. El-Komy and A. Mohamed, 1997. Some pharmacodynamic and biochemical aspects of cefamandole. Dtsch. Tierarztl. Wochenschr., 104: 481-487.

Goto, A., M. Amano, A. Sakai, M. Hara and N. Takahashi, 1990. General pharmacology of BMY-28100. Jpn. J. Antibiot., 43: 1289-1309.

Goto, A., M. Amano, A. Sakai, M. Hara and N. Takahashi, 1992. General pharmacology of cefepime. Jpn. J. Antibiot., 45: 661-680.

Hasegawa, Y., N. Muto and M. Morita, 1979. General pharmacology of cefadroxil (author's transl). Jpn. J. Antibiot., 32: 1356-1371.

Honda, F., T. Ono, N. Itoh, J. Mori, M. Ohtsuka and T. Kamitani, 1980. General pharmacology of ceftizoxime sodium. Arzneimittelforschung, 30: 1680-1687.

Jankovic, S.M., D. Kouvelas and M. Mitrovic, 1996. Spasmogenic action of â-lactam antibiotics on the gastrointestinal tract of experimental animals. Indian J. Med. Res., 104: 216-222.

Meyers, B.R., E.S. Srulevitch, J. Jacobson and S.Z. Hirschman, 1983. Crossover study of the pharmacokinetics of ceftriaxone administered intravenously or intramuscularly to healthy volunteers. Antibiotic Agents Chemother., 24: 812-814.

Milenov, K. and R. Kalfin, 1996. Cholinergic-nitrergic interactions in the guinea-pig gastric fundus. Neuropeptides, 30: 365-371.

Neu, H.C., 1985. Relation of structural properties of beta-lactam antibiotics to antibacterial activity. Am. J. Med., 79: 2-13.

Neu, H.C., N.J. Meropol and K.P. Fu, 1981. Antibacterial activity of ceftriaxone (Ro 13-9904), a beta-lactamasestable cephalosporin. Antimicro. Agents Chemother., 19: 414-423.

Patel, I.H., R.E. Weinfeld, J. Konikoff and M. Parsonnet, 1982. Pharmacokinetics and tolerance of ceftriaxone in humans after single-dose intramuscular administration in water and lidocaine diluents. Antibiotic Agents Chemother., 21: 957-962.
Takai, A., S. Hirai, I. Watanabe, T. Hiraiwa and N. Abe et al., 1980. General pharmacology of cefoperazone, a new cephalosporin antibiotic (author's trans1). Jpn. J. Antibiot., 33: 994-1018.

Takai, A., S. Hirai, I. Watanabe, T. Hiraiwa and N. Abe et al., 1982. General pharmacology of T-1982, a new cephamycin antibiotic. Jpn. J. Antibiot., 35: 2139-2154.

Ti, T.Y., L. Fortin, J.H. Kreeft, D.S. East, R.I. Ogilvie and P.J. Somerville, 1984. Kinetic disposition of intravenous ceftriaxone in normal subjects and patients with renal failure on hemodialysis or peritoneal dialysis. Antimicrobial Agents Chemother., 25: 83-87.

University of Edinburgh, Department of Pharmacology, 1970. Pharmacological Experiments on Isolated Preparations. 2nd Edn., Churchill Livingstone, Edinburgh, USA., pp: 163.

Valeri, P., B. Martinelli, L.A. Morrone and C. Severini, 1990. Reproducible withdrawal contractions of isolated guinea-pig ileum after brief morphine exposure: Effects of clonidine and nifedipine. J. Pharm. Pharmacol., 42: 115-120.

Waxam, D.J. and J.L. Strominger, 1982. Chemistry and Biology of Beta-Lactam Antibiotics. Academic Press, New York.

Yamaki, Y., Y. Shibazaki, H. Kadosawa, S. Murata, T. Nishimori and F. Kobayashi, 1984. Pharmacological studies on a new cephamycin, MT141. (2) Its effect on preparations of neuromuscular junction, smooth muscle organs and gastro-intestinal system. Jpn. J. Antibiot., 37: 1470-1487.

Zhou, H.H., Y.P. Chan, K. Arnold and M. Sun, 1985. Single-dose pharmacokinetics of ceftriaxone in healthy Chinese adults. Antimicrobial Agents Chemother., 27: 192-196. 